PETIR: Jurnal Pengkajian dan Penerapan Teknik Informatika Vol. 13, No. 1, Maret 2020, P-ISSN 1978-9262, E-ISSN 2655-5018 DOI: https://doi.org/10.33322/petir.v13i1.893

\title{
Perbandingan Metode Newton-Raphson \& Metode Secant Untuk Mencari Akar Persamaan Dalam Sistem Persamaan Non-Linier
}

\author{
Endang Sunandar ${ }^{1}$;ndrianto ${ }^{2}$ \\ ${ }^{1}$ Jurusan Sistem Komputer Universitas Raharja \\ ${ }^{2}$ Jurusan Teknik Informatika Institut Teknologi PLN \\ 1endang.sunandar@raharja.info \\ 2indrianto@itpln.ac.id
}

\begin{abstract}
The numerical method is a technique used to formulate mathematical problems so that it can be solved using ordinary arithmetic operations. In general, numerical methods are used to solve mathematical problems that cannot be solved by ordinary analytic methods. In the Numerical Method we recognize two types of system of equations, namely the Linear Equation System and the Non-Linear Equation System. Each system of equation has several methods. The Linear Equation System has the Gauss Elimination method, the Gauss-Jordan Elimination method, and the LU (Lower-Upper) Decomposition method. The Non-Linear Equation Systems has the Bisection method, the Regula Falsi method, the Newton Raphson method, the Secant method, and the Fix Iteration method. In this study, researchers are interested in analyzing 2 methods in the Non-Linear Equation System, the Newton-Raphson method and the Secant method. This analysis process uses the Java programming language tools. It is to facilitate the analysis of method completion algorithm, and monitoring in terms of execution time and analysis of output results so we can clearly know the difference between what happens between the two methods.
\end{abstract}

Keywords: Newton Raphson Method, Secant Method, System of Non-Linear Equations

\begin{abstract}
ABSTRAK
Metode Numerik merupakan suatu teknik yang digunakan untuk memformulasikan persoalan matematika sehinga dapat diselesaikan dengan menggunakan operasi aritmatika biasa. Pada umumnya metode numerik digunakan untuk menyelesaikan persoalan matematika yang tidak dapat diselesaikan dengan metode analitik biasa. Dalam Metode Numerik kita mengenal dua buah jenis sistem persamaan yaitu Sistem Persamaan Linier dan Sistem Persamaan Non-Linier. Masingmasing sistem persamaan memiliki beberapa metode. Dalam Sistem Persamaan Linier diantara metodenya adalah metode Eliminasi Gauss, metode Eliminasi Gauss-Jordan, metode Dekomposisi LU (Lower-Upper). Dan untuk Sistem Persamaan Non-Linier diantara metodenya adalah metode Bisection (Bagi-Dua), metode Regula Falsi, metode Newton Raphson, metode Secant, dan metode Fix Iteration. Dalam penelitian ini, peneliti tertarik untuk menganalisis 2 buah metode yang ada dalam Sistem Persamaan Non-Linier, yaitu metode Newton-Raphson dan metode Secant. Dan proses analisis ini menggunakan perangkat bahasa pemrograman Java, hal ini untuk memudahkan dalam hal analisis algoritma penyelesaian metode, dan monitoring dalam hal waktu eksekusi dan analisis hasil output. Sehinga kita dapat secara jelas mengetahui perbedaan apa saja yang terjadi diantara ke-dua buah metode tersebut.
\end{abstract}

Kata kunci: Metode Newton Raphson, Metode Secant, Sistem Persamaan Non-Linier 
PETIR: Jurnal Pengkajian dan Penerapan Teknik Informatika

\section{PENDAHULUAN}

Seperti kita ketahui bersama bahwa Sistem Persamaan Non-Linier adalah suatu Sistem Persamaan yang digunakan untuk menghitung Akar Persamaan Non-Linier menggunakan satu variable $X, f(x)$, atau secara umum dituliskan dengan formula: $f(x)=0$.

Beberapa metode yang ada diantaranya adalah metode Bisection, metode Regula Falsi, metode Newton Raphson dan metode Secant. Dan dalam penelitian ini peneliti menggunakan 2 buah metode yaitu Newton Raphson dan Secant. Dengan pertimbangan bahwa ke-2 metode ini adalah metode lanjutan yang digunakan dalam penyelesaian Sistem Persamaan Non-Linier.

Tujuan penelitian ini adalah untuk mengetahui perbedaan penyelesaian Sistem Persamaan Non-Linier dengan metode Newton Raphson dan metode Secant menggunakan bahasa Java.

Penelitian sebelumnya yang pernah ada adalah "Analisis dan Implementasi Metode Newton Raphson"[1]. Dalam penelitian tersebut digambarkan tentang salah satu kendala dalam pemakaian metode Newton Raphson adalah keharusan menghitung nilai turunan fungsi, hal yang tidak selalu mudah jika dilakukan secara manual, terutama untuk fungsi-fungsi tertentu. Penelitian selanjutnya adalah "Implementasi Newton Raphson Termodifikasi pada Prediksi Distribusi Tekanan Pipa Transmisi Gas Alam"[2], dimana disampaikan bahwa dengan menggunakan metode Newton Raphson dapat menghasilkan pengukuran hasil distribusi tekanan yang akurat, dengan error relative maksimum $0.28 \%$ untuk batas toleransi error. Sedangkan dalam penelitian "Metode Secant Midpoint Newton untuk Menyelesaikan Persamaan NonLinear"[3] disebutkan bahwa metode ini memerlukan 2 kali evaluasi fungsi dan 2 kali evaluasi turunan pertama fungsi, dan metode ini memiliki orde kekonvergenan empat.

\section{METODE/PERANCANGAN PENELITIAN}

Pada penelitian ini, peneliti menggunakan 2 buah metode yaitu Newton Raphson dan Secant. Masing-masing metode memiliki formulasi dalam penyelesaiannya. Pada metode Newton Raphson rumus untuk mencari nilai $\mathrm{n}$ berikutnya sangat sederhana, sedangkan pada metode Secant rumus untuk mencari nilai $n$ berikutnya agak kompleks. Untuk implementasi dari masing-masing formulasi tersebut peneliti menggunakan bahasa program JAVA.

\subsection{Metode Newton Raphson}

Metode ini memiliki 2 buah formulasi yaitu:

1. Formula untuk mencari nilai variable $\mathrm{X}$ berikutnya, yaitu sebagai berikut:

$$
\mathrm{X}_{\mathrm{n}+1}=\mathrm{X}_{\mathrm{n}}-\left(\mathrm{F}\left(\mathrm{X}_{\mathrm{n}}\right) / \mathrm{F}^{\prime}\left(\mathrm{X}_{\mathrm{n}}\right)\right)
$$

Dalam formula ini terdapat fungsi turunan dari fungsi $X$ yaitu dengan notasi $F^{\prime}(X n)$. Posisi dari F'(Xn) ini adalah sebagai Penyebut Pembagian, sedangkan posisi dari $F(X n)$ sebagai Pembilang Pembagian. Selanjutnya hasil dari proses pembagian ini akan mengurangi nilai Xn pada tahapan yang sedang berjalan.

Jika dinotasikan dalam bentuk tabel dapat digambarkan sebagai berikut: 
PETIR: Jurnal Pengkajian dan Penerapan Teknik Informatika Vol. 13, No. 1, Maret 2020, P-ISSN 1978-9262, E-ISSN 2655-5018 DOI: https://doi.org/10.33322/petir.v13i1.893

Tabel 1. Formulasi Nilai Variabel $\mathrm{X}_{\mathrm{n}}$

\begin{tabular}{|c|c|c|c|c|}
\hline No & $\begin{array}{c}\text { Notasi } \\
\text { Variabel } \mathrm{X}\end{array}$ & $\begin{array}{c}\text { Fungsi } \\
\mathrm{X}\end{array}$ & $\begin{array}{c}\text { Turunan } \\
\text { Fungsi } \mathrm{X}\end{array}$ & $\begin{array}{c}\text { Formula } \\
\mathrm{X}_{\mathrm{n}+1}\end{array}$ \\
\hline & $\mathrm{A}$ & $\mathrm{B}$ & $\mathrm{C}$ & $\mathrm{D}=\mathrm{A}-(\mathrm{B} / \mathrm{C})$ \\
\hline 1 & $\mathrm{X}_{1}$ & $\mathrm{~F}\left(\mathrm{X}_{1}\right)$ & $\mathrm{F}^{\prime}\left(\mathrm{X}_{1}\right)$ & $\mathrm{X}_{2}=\mathrm{X}_{1}-\left(\mathrm{F}\left(\mathrm{X}_{1}\right) / \mathrm{F}^{\prime}\left(\mathrm{X}_{1}\right)\right)$ \\
\hline 2 & $\mathrm{X}_{2}$ & $\mathrm{~F}\left(\mathrm{X}_{2}\right)$ & $\mathrm{F}^{\prime}\left(\mathrm{X}_{2}\right)$ & $\mathrm{X}_{3}=\mathrm{X}_{2}-\left(\mathrm{F}\left(\mathrm{X}_{2}\right) / \mathrm{F}^{\prime}\left(\mathrm{X}_{2}\right)\right)$ \\
\hline 3 & $\mathrm{X}_{3}$ & $\mathrm{~F}\left(\mathrm{X}_{3}\right)$ & $\mathrm{F}^{\prime}\left(\mathrm{X}_{3}\right)$ & $\mathrm{X}_{4}=\mathrm{X}_{3}-\left(\mathrm{F}\left(\mathrm{X}_{3}\right) / \mathrm{F}^{\prime}\left(\mathrm{X}_{3}\right)\right)$ \\
\hline$\ldots$ & $\ldots \ldots$ & $\ldots \ldots$ & $\ldots \ldots$ & $\ldots \ldots$ \\
\hline $\mathrm{m}$ & $\mathrm{X}_{\mathrm{m}}$ & $\mathrm{F}\left(\mathrm{X}_{\mathrm{m}}\right)$ & $\mathrm{F}^{\prime}\left(\mathrm{X}_{\mathrm{m}}\right)$ & $\mathrm{Xm}+1=\mathrm{X}_{\mathrm{m}}-\left(\mathrm{F}\left(\mathrm{X}_{\mathrm{m}}\right) / \mathrm{F}^{\prime}\left(\mathrm{X}_{\mathrm{m}}\right)\right)$ \\
\hline
\end{tabular}

Terlihat pada table di atas pada kolom D bahwa untuk mendapatkan nilai X langkah berikutnya adalah berdasarkan nilai $X$, nilai fungsi $X$, dan nilai turunan fungsi $X$ pada tahapan yang sedang berjalan. Keputusan suatu langkah pencarian akar persamaan dilanjutkan atau dihentikan sangat bergantung pada nilai Absolut Galat Relatif yang dibandingkan dengan nilai Toleransi Error. Pembahasan lebih detail mengenai Galat Relatif pada sub-bab berikutnya.

2. Formula untuk mencari nilai Absolut Galat Relatif yaitu:

$$
\left|\sum X_{n}\right|=\left|X_{n}-X_{n-1}\right| /\left|X_{n}\right|
$$

Variable nilai Absolut Galat Relatif digunakan sebagai penentu apakah tahapan proses pencarian akar persamaan dilanjutkan atau dihentikan. Pada setiap tahapan proses pencarian, variabel nilai Absolut Galat Relatif ini akan dibandingkan dengan nilai Toleransi Error, jika nilai Absolut Galat Relatif ini masih lebih besar dari nilai Toleransi Error maka proses pencarian akar persamaan terus dilanjutkan, hingga nilai Absolut Galat Relatif lebih kecil dari nilai Toleransi Error.

Jika langkah proses pencarian akar persamaan berhenti maka akar persamaannya sudah didapatkan, yaitu suatu nilai yang berada pada variable $X_{n}$. Seperti dapat dilihat pada output program dari metode Secant.

Berikut tabel 2 tentang Formulasi Nilai Absolut Galat Relatif.

Tabel 2. Formulasi Nilai Absolut Galat Relatif

\begin{tabular}{|c|c|c|}
\hline No & $\begin{array}{c}\text { Notasi } \\
\text { Variabel } \mathrm{X}\end{array}$ & $\begin{array}{c}\text { Nilai Absolut Galat Relatif } \\
\left|\sum \mathrm{X}_{\mathrm{n}}\right|\end{array}$ \\
\hline & $\mathrm{A}$ & $\mathrm{B}$ \\
\hline 1 & $\mathrm{X}_{1}$ & - \\
\hline 2 & $\mathrm{X}_{2}$ & $\left|\sum \mathrm{X}_{2}\right|=\left|\mathrm{X}_{2}-\mathrm{X}_{1}\right| /\left|\mathrm{X}_{2}\right|$ \\
\hline 3 & $\mathrm{X}_{3}$ & $\left|\sum \mathrm{X}_{3}\right|=\left|\mathrm{X}_{3}-\mathrm{X}_{2}\right| /\left|\mathrm{X}_{3}\right|$ \\
\hline
\end{tabular}

Pengertian nilai Absolut dari suatu bilangan adalah bahwa bilangan tersebut akan selalu bernilai positif. Jika bilangan tersebut adalah negative maka akan menjadi positif. Jika bilangan tersebut adalah positif maka akan tetap menjadi positif. 
PETIR: Jurnal Pengkajian dan Penerapan Teknik Informatika

\subsection{Metode Secant}

Metode Secant ini hanya memiliki sebuah formulasi saja untuk mencari nilai Variabel $\mathrm{X}$ berikutnya, yaitu:

$$
\mathrm{X}_{\mathrm{n}+1}=\mathrm{X}_{\mathrm{n}}-\left(\left(\mathrm{f}\left(\mathrm{X}_{\mathrm{n}}\right) *\left(\mathrm{X}_{\mathrm{n}}-\mathrm{X}_{\mathrm{n}-1}\right)\right) /\left(\mathrm{f}\left(\mathrm{X}_{\mathrm{n}}\right)-\mathrm{f}(\mathrm{Xn}-1)\right)\right)
$$

Jika dibandingkan dengan metode Newton Raphson, bahwa formulasi di metode Secant lebih kompleks, hanya saja memiliki sebuah formulasi saja. Sedangkan pada metode Newton Raphson formulasinya sangat sederhana sekali, tetapi memiliki 2 buah formulasi yaitu formulasi nilai Variabel $\mathrm{X}$ berikutnya dan formulasi nilai Absolut Galat Relatif.

Pada metode ini terdapat 2 buah variable $\mathrm{X}$ awal untuk proses mencari akar persamaannya. Dan faktor yang menentukan langkah proses perhitungan dilanjutkan atau tidak adalah dengan dibandingkannya nilai variable Absolute Fungsi $\mathrm{X}\left|\mathrm{f}\left(\mathrm{X}_{\mathrm{n}}\right)\right|$ dengan nilai Toleransi Error pada langkah tersebut. Jika nilai variable Absolute Fungsi $\mathrm{X}\left|\mathrm{f}\left(\mathrm{X}_{\mathrm{n}}\right)\right|$ masih lebih besar dari nilai Toleransi Error maka proses pencarian akar persamaan terus dilanjutkan, jika tidak maka proses dihentikan. Dan nilai akar persamaan yang dicari adalah suatu nilai yang berada pada variable $X_{n}$.

\section{HASIL DAN PEMBAHASAN}

Untuk mengimplementasikan penelitian ini, peneliti menggunakan bahasa program Java baik untuk metode Newton Raphson maupun metode Secant. Masing-masing programnya adalah sebagai berikut:

\subsection{Metode Newton Raphson}

\section{- Program Java untuk Metode Newton Raphson}

/*

* @ author Ir. Endang Sunandar,M.Kom

$* /$

import java.text.DecimalFormat;

public class newtonRaphson \{

public static void main(String args[])\{

DecimalFormat digit=new DecimalFormat("00.00000");

double $\mathrm{xn}=3.00$; double $\mathrm{fxn}=0.00$; double toleransi $=0.005$;

double faksen $=0.00$; double $\mathrm{xnNext}=0.00$; int no $=1$; double $\mathrm{EXn}=1500.00$;

$\mathrm{fxn}=(4 *(\mathrm{xn} * \mathrm{xn} * \mathrm{xn}))-\left(15^{*}(\mathrm{xn} * \mathrm{xn})\right)+(17 * \mathrm{xn})-6 ;$ double ExnCetak $=0.00$;

faksen $=(12 *(x n * x n))-(30 * x n)+17$; String kol="";

System.out.println("Penyelesaian SPNL dengan Metode Newton Raphson");

System.out.println $\left(" \mathrm{f}(\mathrm{x})=4 \mathrm{X}^{\wedge} 3-15 \mathrm{X}^{\wedge} 2+17 \mathrm{X}-6\right.$ maka $\left.\mathrm{f}^{\prime}(\mathrm{x})=12 \mathrm{X}^{\wedge} 2-30 \mathrm{X}+17 "\right)$;

System.out.print $\ln (" \mathrm{Xn}=3$; Toleransi Error $=0.005 ")$;

System.out.println("------------------------------------");

System.out.println("| No | Xn | f(Xn) | $\mathrm{f}^{\prime}(\mathrm{Xn})$ | |EXn| |");

System.out.println("----------------------------------------");

System.out.print( "| "+no+" | ");

System.out.print(digit.format(xn));

if $(f x n<0)\{$

System.out.print(" | ");

\}else \{

System.out.print(" | "); $\quad$ \} 
PETIR: Jurnal Pengkajian dan Penerapan Teknik Informatika Vol. 13, No. 1, Maret 2020, P-ISSN 1978-9262, E-ISSN 2655-5018 DOI: https://doi.org/10.33322/petir.v13i1.893

System.out.print(digit.format(fxn)+" | ");

System.out.print(digit.format(faksen)+" | ");

System.out.print(" - |");

System.out.println();

while $(\mathrm{EXn}>$ toleransi $)\{$

no $=$ no $+1 ; x n N e x t=x n-(f x n / f a k s e n) ;$

$\mathrm{fxn}=\left(4 *\left(\mathrm{xnNext} * \mathrm{xnNext}^{*} \mathrm{xnNext}\right)\right)-\left(15^{*}(\mathrm{xnNext} * \mathrm{xnNext})\right)+(17 * \mathrm{xnNext})-6$;

faksen $=(12 *(x n N e x t * x n N e x t))-(30 * x n N e x t)+17$;

System.out.print( "| "+no+" | ");

System.out.print(digit.format(xnNext));

if $(\mathrm{fxn}<0)\{$

System.out.print(" | ");

\}else \{ System.out.print(" | "); \}

System.out.print(digit.format(fxn)+" | ");

System.out.print(digit.format(faksen)+" |");

$\mathrm{EXn}=(\mathrm{xnNext}-\mathrm{xn}) / \mathrm{xnNext}$;

if $(\mathrm{EXn}<0)$ \{

kol=" | ";EXn=EXn * -1;ExnCetak=EXn;

\}else $\{$ kol=" | ";ExnCetak=EXn; $\}$

System.out.println(digit.format(ExnCetak)+kol);

$\mathrm{xn}=\mathrm{xnNext}$

\}System.out.println(" ");

System.out.println("Maka Nilai Akar Persamaan yang dicari adalah : "+digit.format $(\mathrm{xnNext}))$;

System.out.println("");

\}

\}

\section{- Output Program Java untuk Metode Newton Raphson}

Penyelesaian SPNL dengan Metode Newton Raphson

$\mathrm{f}(\mathrm{x})=4 \mathrm{X}^{\wedge} 3-15 \mathrm{X}^{\wedge} 2+17 \mathrm{X}-6$ maka $\mathrm{f}^{\prime}(\mathrm{x})=12 \mathrm{X}^{\wedge} 2-30 \mathrm{X}+17$

$\mathrm{Xn}=3$; Toleransi Error $=0.005$

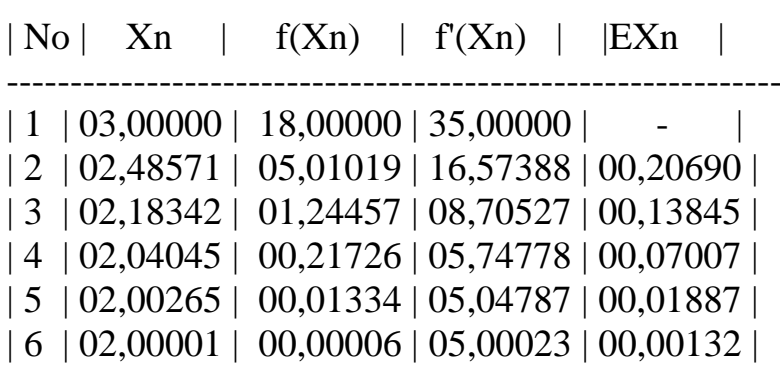

Maka Nilai Akar Persamaan yang dicari adalah : 02,00001

BUILD SUCCESSFUL (total time: 1 second)

Terlihat bahwasannya dengan menggunakan metode Newton Raphson jumlah langkah penyelesaian untuk mencari akar persamaannya adalah sebanyak 6 langkah. 


\subsection{Metode Secant}

\section{- Program Java untuk Metode Secant}

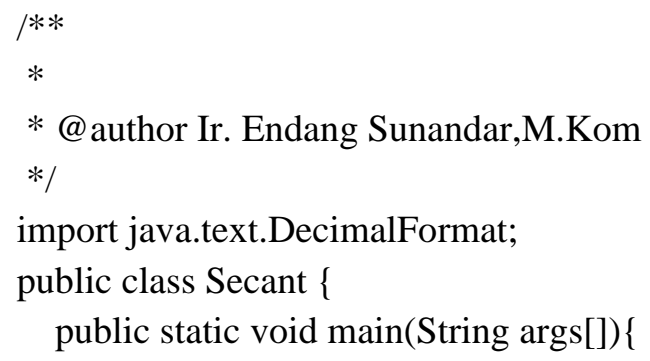


PETIR: Jurnal Pengkajian dan Penerapan Teknik Informatika Vol. 13, No. 1, Maret 2020, P-ISSN 1978-9262, E-ISSN 2655-5018 DOI: https://doi.org/10.33322/petir.v13i1.893

System.out.print(kol);System.out.print (digit.format(fxnLanjut)+kol);

if (fxnLanjut <0) \{absfxnLanjut=fxnLanjut *-1; \}else $\{$ absfxnLanjut=fxnLanjut; $\}$

System.out.print(digit.format(absfxnLanjut)+" |");System.out.println("');

// if $($ no= $=6)$ (break; $\}$

absfxnNext=absfxnLanjut;

$\mathrm{xn}=\mathrm{xnNext} ; \mathrm{fxn}=\mathrm{fxnNext}$;

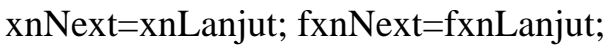

\}

System.out.println(" "); \} \}

\section{- Output Program Java untuk Metode Secant}

run:

Penyelesaian SPNL dengan Metode SECANT

$\mathrm{f}(\mathrm{x})=4 \mathrm{X}^{\wedge} 3-15 \mathrm{X}^{\wedge} 2+17 \mathrm{X}-6$

$\mathrm{Xn}=-1$, dan $\mathrm{Xn}+1=3$; Toleransi Error $=0.005$

\begin{tabular}{|c|c|c|c|}
\hline & $\mathrm{Xn}$ & $f(X n)$ & $|f(X n)|$ \\
\hline & -01. & -42 & \\
\hline 2 & 03.00000 & 18.00000 & 000 \\
\hline 3 & 01.80000 & -00. & 00. \\
\hline 4 & 01.84319 & -00 & 00. \\
\hline 5 & 02 & 00 & 00 \\
\hline 6 & 01. & -00 & 00. \\
\hline I & & $\mid-00.0$ & | 00.0 \\
\hline 8 & 02.00036 & 00.0017 & 00.00178 \\
\hline
\end{tabular}

Maka Nilai Akar Persamaan yang dicari adalah: 02,00036

BUILD SUCCESSFUL (total time: 0 seconds)

Terlihat bahwasanya dengan menggunakan metode Secant, jumlah langkah penyelesaian untuk mencari akar persamaannya adalah sebanyak 8 langkah.

\section{KESIMPULAN DAN SARAN}

Berdasarkan hasil penelitian pada perbandingan 2 metode, yaitu metode Newton Raphson dan metode Secant maka dapat diambil beberapa kesimpulan sebagai berikut:

1. Metode Newton Raphson memiliki 2 buah formulasi yaitu formulasi nilai Variabel X berikutnya, dan formulasi nilai Absolut Galat Relatif.

2. Metode Secant hanya memiliki sebuah formulasi nilai Variabel $\mathrm{X}$ berikutnya.

3. Formulasi nilai Variabel X berikutnya pada metode Secant lebih komplek dibandingkan dengan metode Newton Raphson.

4. Kecepatan proses perhitungan untuk mencari nilai akar persamaan adalah pada metode Newton Raphson (hanya 6 langkah), sedangkan pada metode Secant ada 8 langkah. Hal ini dikarenakan pada metode Newton Raphson terdapat tambahan 1 formulasi yaitu formulasi nilai Absolut Galat Relatif.

5. Nilai akar persamaan yang dicari lebih akurat dengan metode Newton Raphson, yaitu 2,00001, sedangkan pada metode Secant yaitu 2,00036, ada selisih sekitar 0,00035. 
PETIR: Jurnal Pengkajian dan Penerapan Teknik Informatika Vol. 13, No. 1, Maret 2020, P-ISSN 1978-9262, E-ISSN 2655-5018 DOI: https://doi.org/10.33322/petir.v13i1.893

\section{DAFTAR PUSTAKA}

[1] Sahid, [2003],"Analisis dan Implementasi Metode Newton Raphson", Jurusan Matematika Fakultas FMIPA, Universitas Negeri Jogjakarta.

[2] Aditsania Annisa, Kurniawan Isman, [2016], "Implementasi Newton Raphson Termodifikasi pada Prediksi Distribusi Tekanan Pipa Transmisi Gas Alam”,Jl. Telekomunikasi Terusan Buah Batu Bandung, Telkom University.

[3] Putra Supriadi, [2014], "Metode Secant - Midpoint Newton untuk Menyelesaikan Persamaan Non-Liniear", LabKom FMIPA Fakultas Sains dan Teknologi, Universitas Riau.

[4] E. Sunandar, "Perbandingan Metode Selection Sort dan Insertion Sort Dalam Pengurutan Data Menggunakan Bahasa Program Java”, petir, vol. 12, no. 2, pp. 172 - 178, Sep. 2019.

[5] Rahayuni IA, Dharmawan K, Harini LP. Perbandingan Keefisienan Metode Newton-Raphson, Metode Secant, Dan Metode Bisection Dalam Mengestimasi Implied Volatilities Saham. EJurnal Matematika. 2016;5(1):1-6.

[6] Wulan ER, Sukarti SM, Zulkarnaen D. Perbandingan Tingkat Kecepatan Konvergensi dari Metode Newton Raphson dan Metode Secant Setelah Mengaplikasikan Metode Aiken's dalam Perhitungan Akar Pangkat Tiga. Jurnal Matematika Integratif ISSN. 2017;1412:6184.

[7] Batarius P. Perbandingan Metode Newton-Raphson Modifikasi dan Metode Secant Modifikasi Dalam Penentuan Akar Persamaan. InProsiding, Seminar nasional Riset Dan Teknologi Terapan 2018 (Vol. 8).

[8] Guspari O. Penerapan Metode Bisection Dan Metode Secant Dalam Rekayasa Sipil (Studi KasusPembuatan Diagram Interaksi Kolom Beton Bertulang). Rekayasa Sipil. 2007;3(2):6875 .

[9] R. Siregar, Z. Siregar, and R. Arianto, "Klasifikasi Sentiment Analysis Pada Komentar Peserta Diklat Menggunakan Metode K-Nearest Neighbor", kilat, vol. 8, no. 1, May 2019.

[10] Y. Arvio, I. Sangadji, H. Sikumbang, and M. Anjarwati, "Pendekatan Implementasi Model Substractive Clustering Dalam Memetakan Dan Klasifikasi Data Perilaku Konsumen Listrik Tegangan Rendah Studi Kasus : Pelanggan PT PLN (Persero) UP3 Cengkareng”, petir, vol. 12, no. 2, pp. 251 - 261, Sep. 2019.

[11] N. Budiana, R. Siregar, and M. Susanti, "Penetapan Instruktur Diklat Menggunakan Metode Clustering K-Means dan Topsis Pada PT PLN (Persero) Udiklat Jakarta”, petir, vol. 12, no. 2, pp. 111 - 121, Aug. 2019.

[12] E. Sunandar, "Perbandingan Metode Selection Sort dan Insertion Sort Dalam Pengurutan Data Menggunakan Bahasa Program Java", petir, vol. 12, no. 2, pp. 172 - 178, Sep. 2019.

[13] Siswipraptini PC, Aziza RN, Sangadji IB, Indrianto I, Siregar RR. Automated Smart Home Controller Based on Adaptive Linear Neural Network. In2019 7th International Conference on Control, Mechatronics and Automation (ICCMA) 2019 Nov 6 (pp. 423-427). IEEE.

[14] Panjaitan M. Pemahaman Metode Numerik Menggunakan Pemprogrman Matlab (Studi Kasus: Metode Secant). JurTI (Jurnal Teknologi Informasi). 2017 Jun 1;1(1):89-94.

[15] Jumawanti I, Sutrisno S, Surarso B. Hasil Perbandingan Metode Improved Newton-Raphson Berbasis Dekomposisi Adomian Dan Beberapa Metode Klasik Pada Masalah Persamaan NonLinier. Journal of Fundamental Mathematics and Applications (JFMA). 2018 Jul 4;1(1):3944. 